\title{
Cadmium Sulfide (CdS) Based Thin Films for Photo Sensing Application
}

\author{
Bangaru. Ravi Kumar ${ }^{1}$,Dr. Samir Ranjan Meher $^{2}$ \\ ${ }^{I} M$. Tech Scholar, Sensor System Technology, School of Electrical Engineering \\ ${ }^{2}$ Dept. of Physics, School of Advanced Science VIT University, Vellore, Tamil Nadu, India, 632014
}

\begin{abstract}
Cadmium Sulfide (CdS) is one of the highly photo sensitive and good semiconductor material of II-VI group elements. Cadmium Sulfide (CdS) have different applications in optoelectronic devices like solar cells, photo detectors etc. In the present work CdS thin films were deposited on ultrasonically cleaned glass substrates using sol-gel spin-coating technique. The structural, optical and surface morphologies of CdS thin films were investigated by X-ray diffraction (XRD) analysis, UV-Visible Spectrum analysis, Atomic Force Microscopy (AFM) and Scanning Electron Microscopy (SEM). The Crystallographic Structure was determined from XRD analysis. It reveals the films were Crystallized in Hexagonal phase with $\left(\begin{array}{lll}0 & 0 & 2\end{array}\right)$ plane. The Band gap is calculated from Tauc's plot from Absorbance Spectrum. The determined Band gap values of CdS thin films Decreases with Increase in Annealing Temperature. AFM gives the roughness of the CdS films. SEM studies reveals that the grains are spherically shaped and distributed uniformly over the entire surface of the glass substrate. Electrical Properties of the Cadmium Sulfide $(C d S)$ thin films were studied with I-V measurement system .
\end{abstract}

Keywords: Sol-gel, Spin Coating, CdS thin Films, UV-Visible,XRD,AFM,SEM.

\section{Introduction}

Cadmium Sulfide (CdS) is a semiconductor material and CdS belongs to metal Chalcogenide group and is having good sophisticated properties. CdS is relatively in-expensive and conventional for practical use and easy to fabricate .This CdS material is having wide band gap of $2.43 \mathrm{eV}$ [1]. CdS is having good optical properties. CdS is a potential candidate to be used as window layer in solar cells good nanopiezo electrical devices, field effect transistors, gas sensing application, light emitting diodes, photo detectors, photo electro chemical cells, photo resistors, etc.

CdS is a yellow coloured material. A photo resistor or photo cell or light dependent resistor is a light controlled variable resistor. The Resistance of the photo resistor changes with the light intensity. When the incident light intensity is increased the resistance of photo resistor decreases. It exhibits photo-conductivity property. If incident light of photo resistor exceeds a certain frequency, photons will be absorbed through the semiconducting material. At this stage semiconductor will give some electrons with high energy to jump from valence band to conduction band. The resulting electron-hole pair and therefore the resistance of the material will automatically decreases. The change in resistance gives the sensitivity of photo resistor. A photo resistors device can either be intrinsic or extrinsic. An intrinsic semiconductor is having its own charge carriers. In intrinsic semiconductors the available electrons are in valence band, so photon must have high energy to excite the electrons across the band gap of the semi conducing material. Extrinsic semiconducting materials have impurities and these are also called as dopants and the ground state energy is nearer to the conduction band, so electrons do not have high energy to jump and hence lower energy photons are needed to trigger the semiconducting material. Photo resistors are less light sensitive than photodiodes or photo transistors. A photoresistor is a passive element and not have PN-junction. The photo resistivity of the photo resistor will vary depending upon the ambient temperature. Photo resistors also exhibits the latency between exposure to light and sub sequent decreases in resistance value, it is usually around in10 milliseconds. The lag time when in dark is even higher, long as one second. This property will not suitable for the fast light sensing applications like flash lights etc.

\section{Experimental Details}

CdS sol-gel has been prepared by using the following two solutions. Solution I was prepared by mixing $0.3 \mathrm{M}$ Cadmium Acetate dihydrate in $50 \mathrm{ml} 2$-methoxyethanol and stirred for 2 hours. Solution II was prepared by mixing $0.3 \mathrm{M}$ Thiourea in $50 \mathrm{ml}$ 2-methoxyethanol and stirred for 2hours. After Solution I and Solution II mixed to gather and $0.95 \mathrm{ml}$ of Monoethanolamine was added and stirred again for 2 hours and aged for 3hours to obtain the final sol-gel for the deposition of thin film.The spin coating method was used to prepare thin films of $\mathrm{CdS}$ by coating the prepared sol-gel onto the glass substrates. The sol-gel spin coating method is basically a chemical deposition method where the desired material is spread on the substrates by spin coating. Prior to deposition the 
substrates were washed with soap solution, acetone and then distilled water. Finally the substrates were ultrasonically cleaned for 30 minutes. And dried with drier. Continuous film was formed onto the substrates by spin deposition of CdS sol - gel with the spin speed and spin time of $1500 \mathrm{rpm}$ and 30 seconds respectively. The films were post annealed in air at $400^{\circ} \mathrm{C}$, with the annealing time of [ hour to remove solvent and organic residuals. Annealing temperature is also one of the parameters, which may influence the stoichometry and structural properties and band gap of the films. So this process was repeated for three more samples with the annealing temperature of $200^{\circ} \mathrm{C}, 300^{\circ} \mathrm{C}$ and $450^{\circ} \mathrm{C}$.

For the prepared CdS thin films X - Ray diffraction (XRO) patterns were obtained using X'PERT PRO $\mathrm{X}$ - ray diffractometer, which was operated at $40 \mathrm{KV}$ and 30rnA with $\mathrm{CuK} \alpha_{1}$ radiation of wavelength $1.5407 \mathrm{~A}$. Optical transmission spectra were recorded in the range of 200 - $1200 \mathrm{~nm}$ using Schimadzu 1800 UV- VIS- NIR spectrophotometer. The Roughness of the CdS films were measured by using Atomic Force Microscopy(AFM). The surface morphology observation and elemental analysis were done by Scanning Electron Microscope(SEM).

\section{A. UV-Visible Analysis}

1.Transmission Analysis

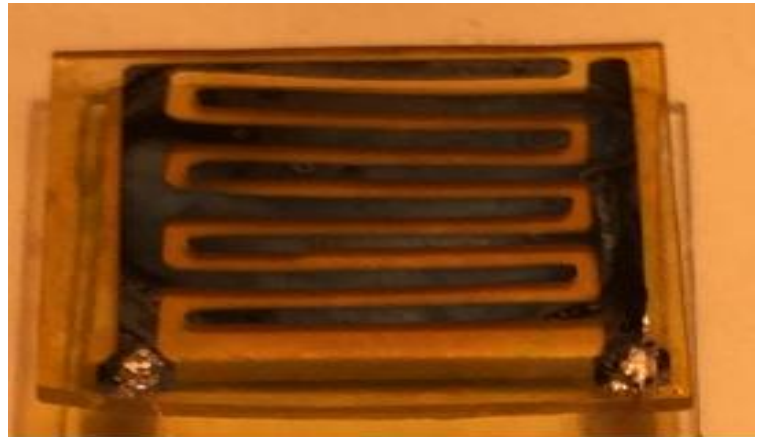

Fig. 1.PVD Electrodes on CdS thin film at 300c

\section{Results And Discussions}

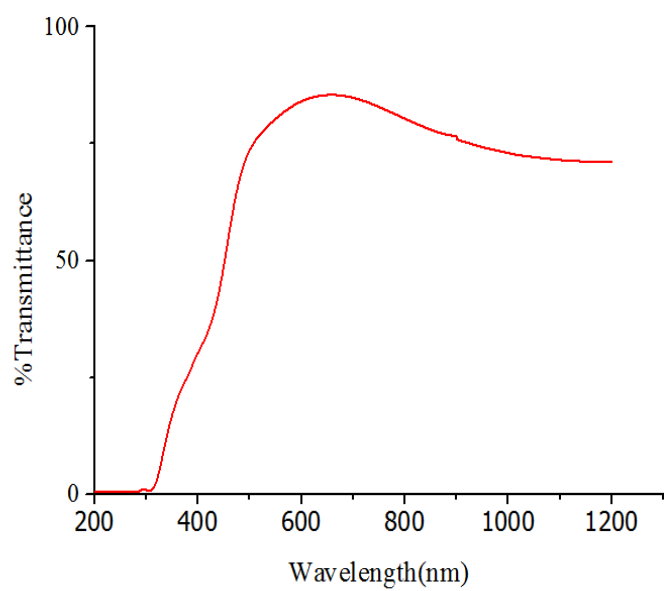

Fig. 1 (a) Transmittance of CdS thin film at $200^{\circ} \mathrm{C}$

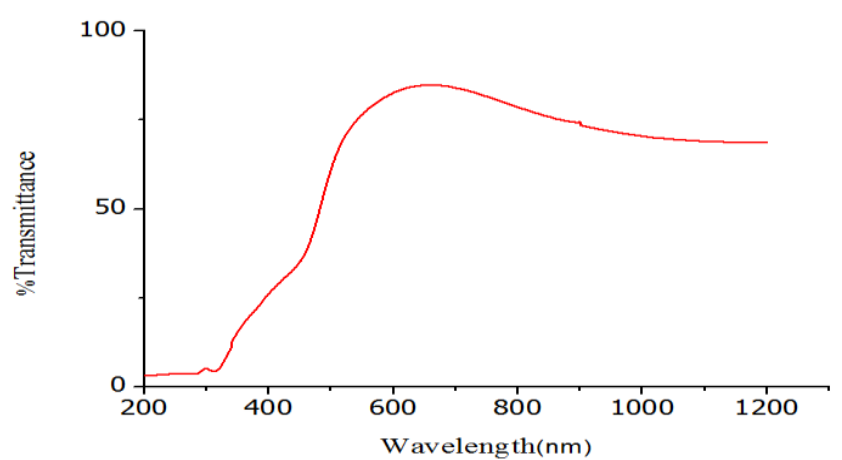

Fig. 1 (b) Transmittance of CdS thin film at $300^{\circ} \mathrm{C}$ 


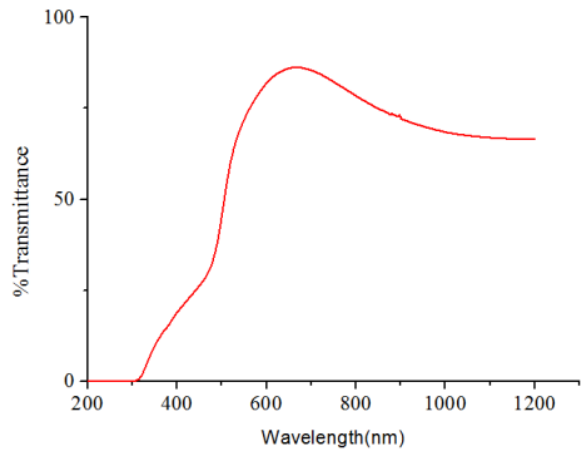

Fig. 1 (c) Transmittance of CdS thin film at $400^{\circ} \mathrm{C}$

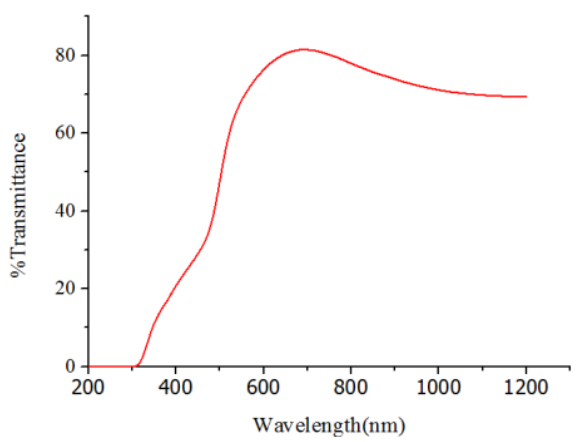

Fig. 1 (d) Transmittance of CdS thin film at $450^{\circ} \mathrm{C}$

Fig. 1 (a),1 (b),1 (c),1 (d) shows the optical Transmittance spectra of the CdS thin films prepared by the spin coating method for different annealing temperatures.

\section{Absorbance Analysis}

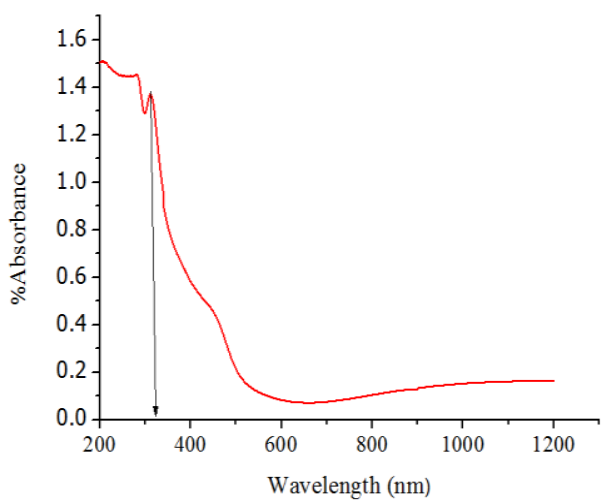

Fig. 2 (a) Absorbance of CdS thin film at $200^{\circ} \mathrm{C}$

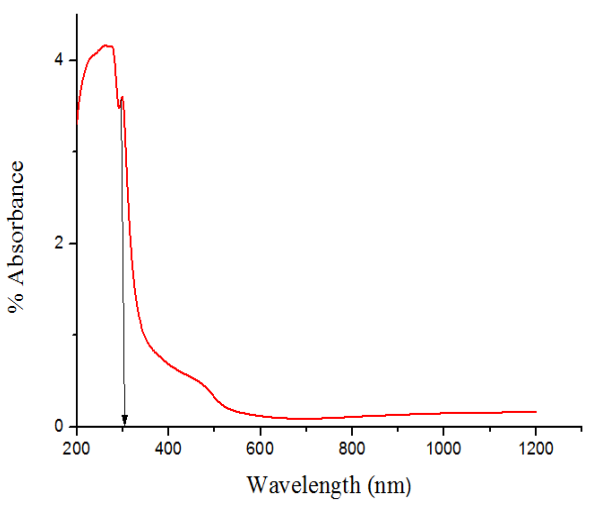

Fig. 2 (b) Absorbance of CdS thin film at $300^{\circ} \mathrm{C}$ 


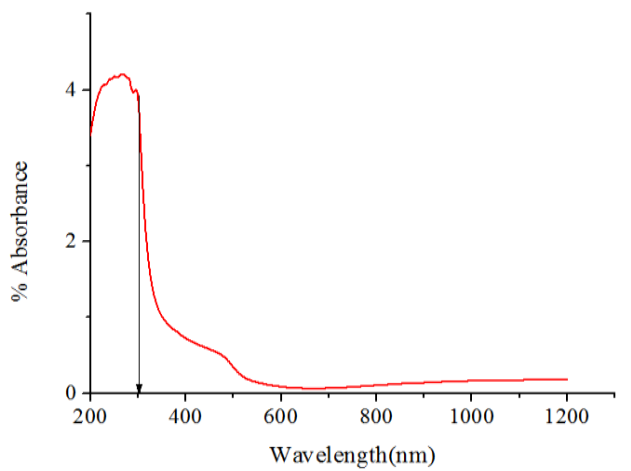

Fig. 2 (c) Absorbance of $\mathrm{CdS}$ thin film at $400^{\circ} \mathrm{C}$

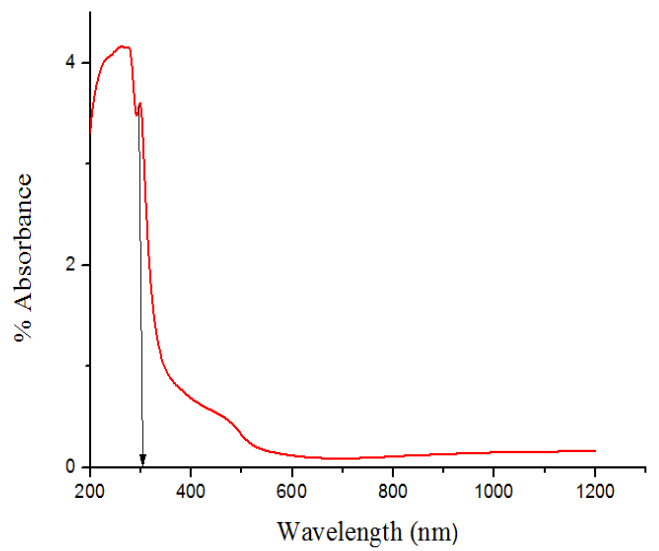

Fig. 2 (d) Absorbance of CdS thin film at $450^{\circ} \mathrm{C}$

Fig. 2 (a),2 (b),2 (c),2 (d) shows the optical Absorbance spectra of the CdS thin films prepared by the spin coating method for different annealing temperatures. The Absorption spectra of the CdS thin films starts at $300 \mathrm{~nm}$.

\section{Tauc's Plot}

The Tauc's plot is used to determine the optical band gap of the semiconductor materials. And a Tauc gap is use to determine the optical properties of amorphous materials. The band gap of a material can be determined from the absorption coefficient vs. wavelength. If the bottom of the conduction band and the top of the valence band are taken to have a parabolic shape, the absorption coefficient (alpha) can be given as below,

$$
\alpha=\mathrm{A}\left(h v-E_{g}\right)^{m}
$$

Here, $\mathrm{A}$ is the constant and $\mathrm{m}$ depends up on the nature of the optical transition. $\mathrm{m}=1 / 2$ for a direct band gap material and $\mathrm{m}=2$ for an indirect band gap material. This Tauc's plot is plotted between $(\alpha h v)^{2}$ vs. ( $h v)$. So, the plot $(\alpha h v)^{2}$ vs. ( hv ) gives a straight line, it is indirect band gap material, and a plot $(\alpha h v)^{2}$ vs. ( $\mathrm{h} v$ ) yields a straight line it is a direct band gap material. Where, $\alpha$ is the absorption coefficient and $\mathrm{h}$ is the Planck's constant and $v$ is the velocity of light. As the Annealing Temperature increased the band gap is reduced.

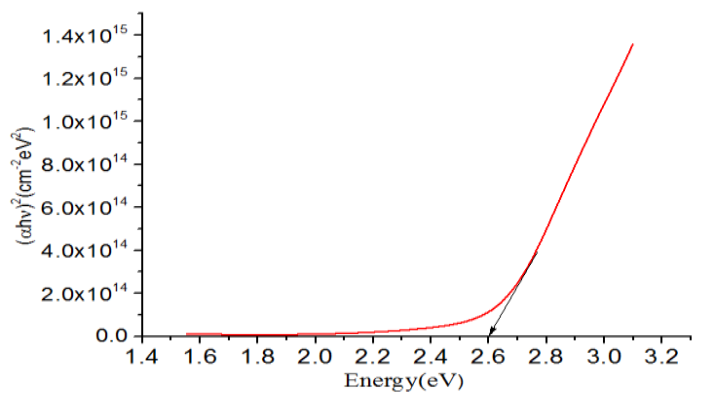

Fig. 3 (a) Tauc's plot of CdS thin film at $200^{\circ} \mathrm{C}$ 


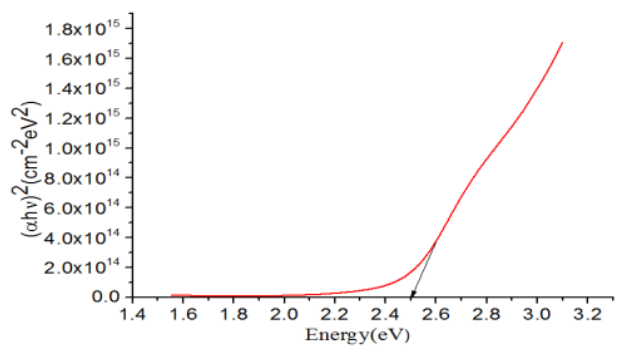

Fig. 3 (b) Tauc's plot of CdS thin film at $300^{\circ} \mathrm{C}$

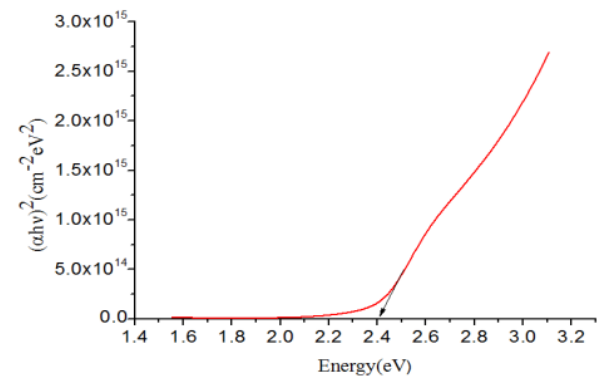

Fig. 3 (c) Tauc's plot of CdS thin film at $400^{\circ} \mathrm{C}$

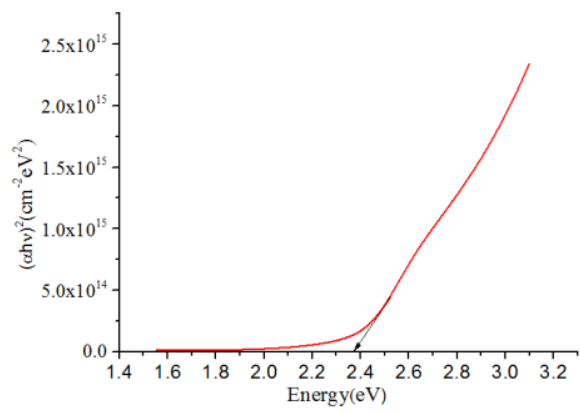

Fig. 3 (d) Tauc's plot of CdS thin film at $450^{\circ} \mathrm{C}$

From the above Tauc's plot analysis Sol-gel spin coated CdS thin films, while increasing Annealing temperature of the CdS Thin films the corresponding band gap values are decreasing. It is shown in below tabular form,

\begin{tabular}{|l|l|}
\hline Annealing Temperature & Band gap $(\mathrm{eV})$ \\
\hline $200^{\circ} \mathrm{C}$ & $2.6 \mathrm{eV}$ \\
\hline $300^{\circ} \mathrm{C}$ & $2.5 \mathrm{eV}$ \\
\hline $400^{\circ} \mathrm{C}$ & $2.4 \mathrm{eV}$ \\
\hline $450^{\circ} \mathrm{C}$ & $2.3 \mathrm{eV}$ \\
\hline
\end{tabular}

\section{B. Structural Analysis}

\section{X-ray diffraction Analysis}

The XRD pattern of CdS thin film coated on glass substrate by sol-gel spin coating method are shown in figure,

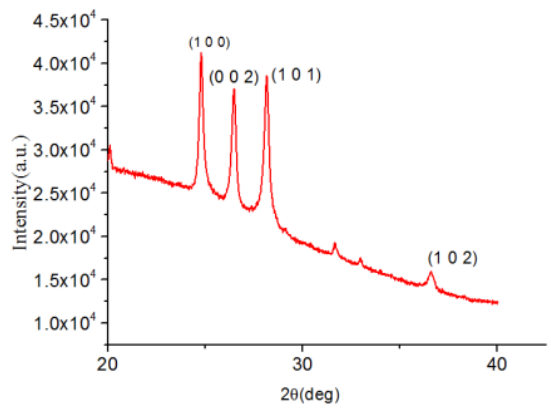

Fig. 3 (a) XRD Pattern of CdS thin film annealed at $400^{\circ} \mathrm{C}$ 
These pattern shows that the annealed film have hexagonal wurtizite structure. The X-ray diffraction pattern of the CdS thin film annealed at $400 \square \mathrm{C}$ was presented in figure 5.1. And the XRD pattern exhibits the typical amorphous broaden peaks observed around $2 \theta=26.2^{\circ}$ and $27^{\circ}$ and $36^{\circ}$ respectively. And the corresponding lattice planes are $\left(\begin{array}{lll}1 & 0 & 0\end{array}\right),\left(\begin{array}{lll}0 & 0 & 2\end{array}\right)$ and $\left(\begin{array}{lll}1 & 1 & 0\end{array}\right)$ and $\left(\begin{array}{lll}1 & 1 & 2\end{array}\right)$ respectively. From these corresponding planes the CdS thin film annealed at $400 \llbracket \mathrm{c}$ was having hexagonal crystallite structure in nature when it is compared to the JCPDS (06-0314).The Debye scherrer's formula will relate the size of sub-micrometer particles and crystallite size. The average crystallite size of the CdS thin film measured is $9.2 \mathrm{~nm}$.

$\mathrm{D}=\frac{K \lambda}{\beta \cos \theta}$

where, D is the mean size of the crystalline domains, which is may be smaller or equal to the grain size. $\mathrm{K}$ is the dimensionless shape factor, value is closed to the unity, the shape factor is considered as 0.94 , but it will varies with the actual crystallite shape. $\lambda$ is the wavelength of X-rays. $\beta$ is the Full width half maximum value.

\section{Atomic Force Microscopy(AFM) analysis}

From the AFM analysis the average roughness of the Cadmium Sulfide(CdS) thin films were determined. The average roughness of the $\mathrm{CdS}$ thin films found to be $7 \mathrm{~nm}$ respectively.

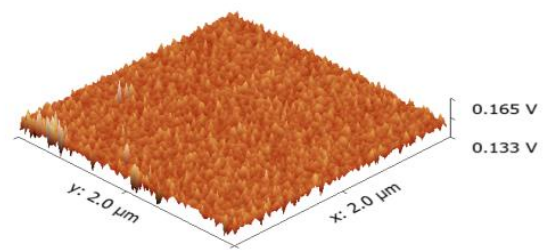

Fig. 4 (a) AFM image of the CdS thin film at $2 \mu \mathrm{m}$ Scanning

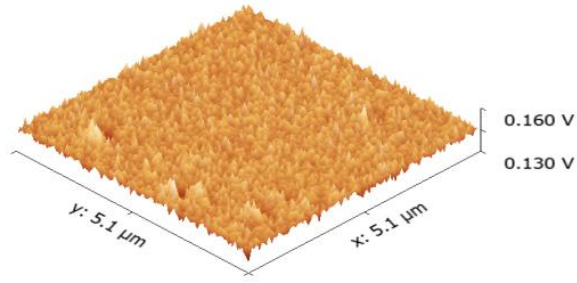

Fig. 4 (b) AFM image of the CdS thin film at $5 \mu \mathrm{mScanning}$

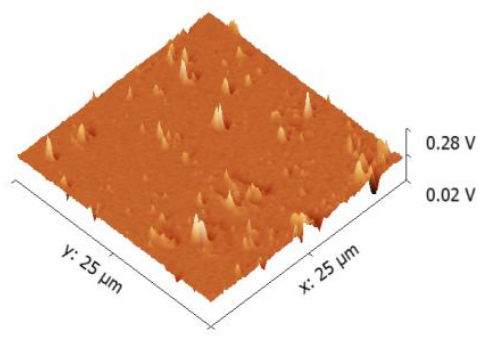

Fig. 4 (c) AFM image of the CdS thin film at $25 \mu \mathrm{m}$ Scanning

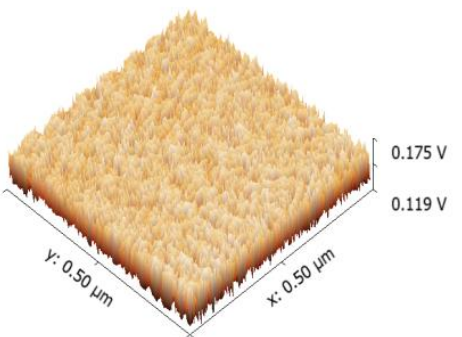

Fig. 4 (d) AFM image of the CdS thin film at $0.50 \mu \mathrm{m}$ Scanning 


\section{Scanning Electron Microscope(SEM) Analysis}

The surface morphology of the Cadmium Sulfide (CdS) thin film is measures by using the Scanning electron microscope. And the surface morphological analysis of the CdS thin film is also measured. The Scanning Electron Microscope analysis of CdS thin film shows in below figure 5(a).

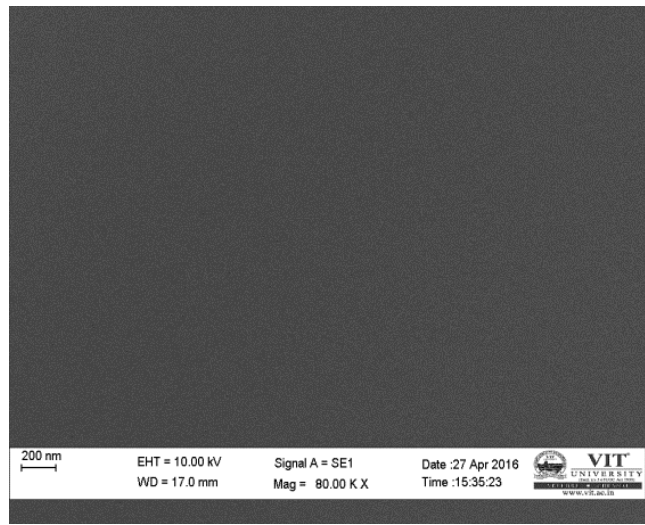

Fig. 5 (a) SEM image of CdS film

\section{E. Electrical characteristics}

\section{I-V Characteristics}

Understanding the electrical properties of the Sol-gel spin coated CdS thin films were recorded by using four - probe Method. Contacts of the CdS thin films were taken and these are connected to the four point probe and measured the dark current and illuminated current and photo response of the CdS thin films were measured. Here the $100 \mathrm{~W}$ visible light is used for the illumination. And the figure 6 (a) and 6 (b) photo current and dark current and light illuminated current was measured for 10 layers coated and 5 layers coated thin films.

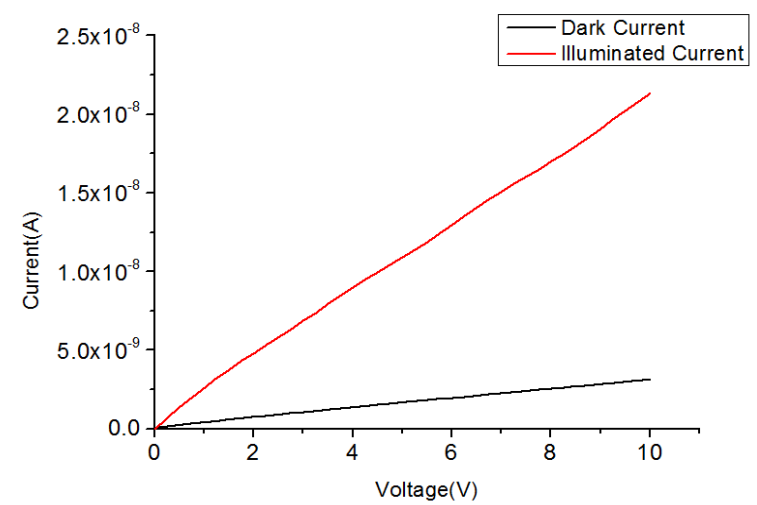

Fig 6 (a) I-V measurement for 10layers deposited film

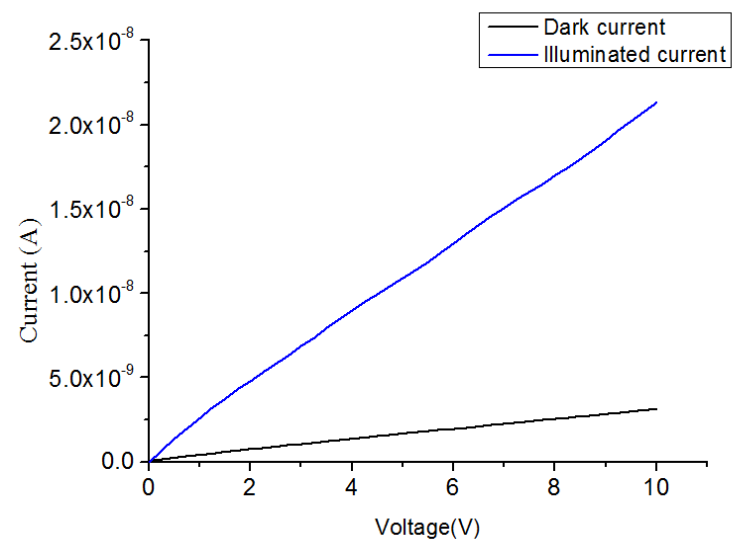

Fig 6 (b) I-V measurements for 5 layers deposited film 


\section{Photo Response}

Here, the photo response of the CdS thin film was measured by using I-V measurement system and the current vs. time plot represents the $\mathrm{ON}$ and $\mathrm{OFF}$ time corresponding to the photo current. The response and recovery time of the $\mathrm{CdS}$ thin film is quicker. Here light source is used as $100 \mathrm{~W}$ visible lamp. Figure 7(a) and 7(b) represents the photo response of the CdS thin films deposited at 10 layers and 5 layers.

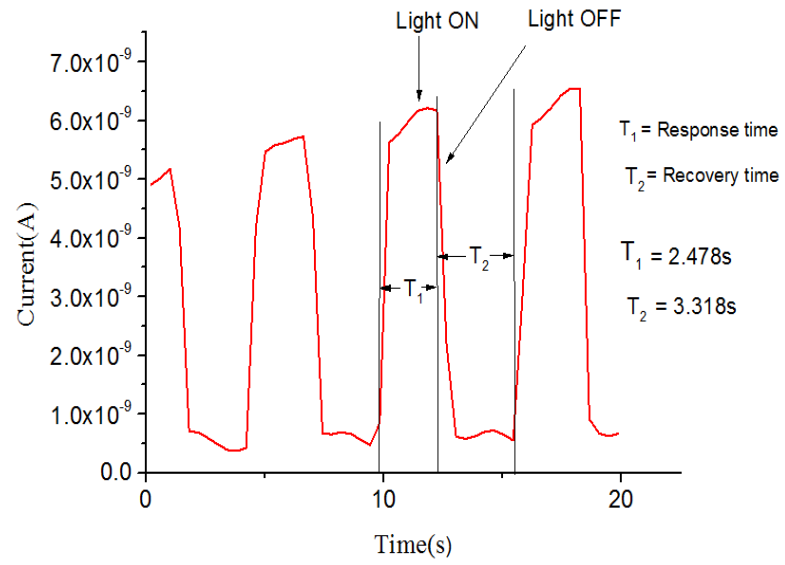

Fig 7 (a) Photo response for 10layers deposited film

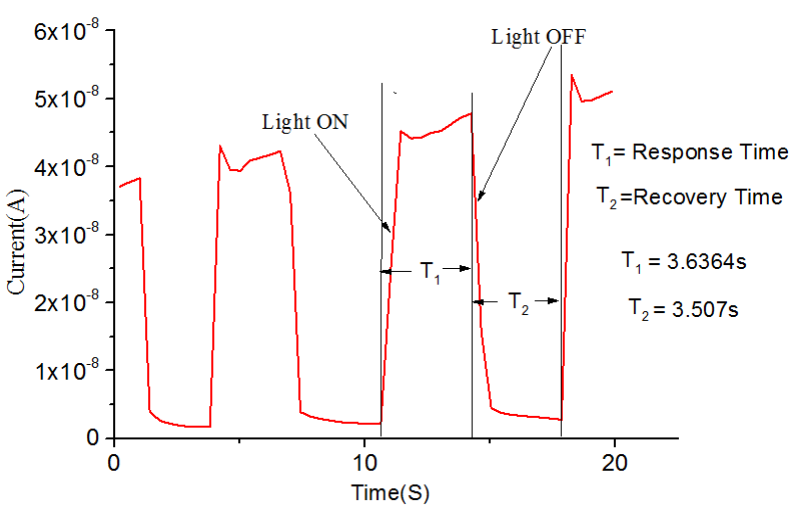

Fig 7 (b) Photo responses for 5 layers deposited film

\section{Sensitivity}

Sensitivity of the CdS thin film is defined as the change in resistance from dark environment to the visible light exposed environment with respect to the dark resistance.

$\operatorname{Sensitivity}(\%)=\frac{R_{d}-R_{i}}{R_{i}}$

here, $R_{d}$ is the Dark Resistance and $R_{i}$ is the Light illuminated Resistance.

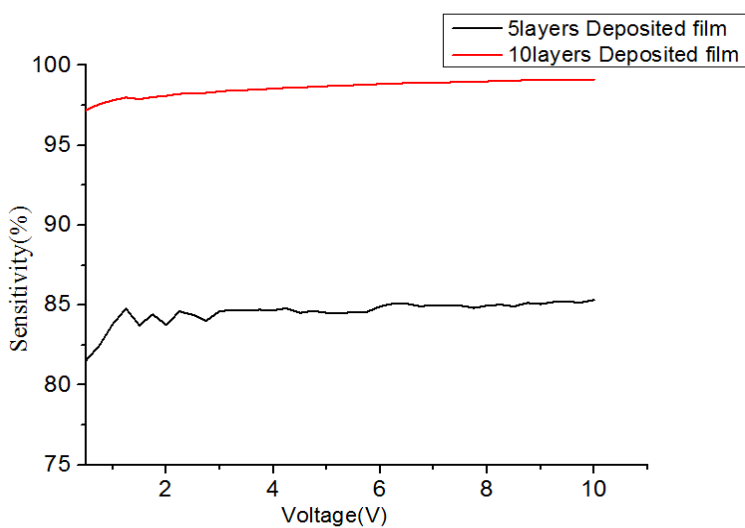

Fig 8 (a) Photo Sensitivity for 10 and 5 layers deposited film 


\section{Conclusion}

It has been successfully, The Cadmium Sulfide (CdS) thin films were deposited by using sol-gel spin coating method. From the UV-Visible analysis the CdS thin films were having good absorption and transmission properties and from the Tauc's plot the band gap values are determined. Here, the band gap is decreased while increasing the annealing temperatures (i.e. $200^{\circ} \mathrm{C}, 300^{\circ} \mathrm{C}, 400^{\circ} \mathrm{C}, 450^{\circ} \mathrm{C}$ ). And the corresponding Band gap values are $2.6 \mathrm{eV}, 2.5 \mathrm{eV}, 2.4 \mathrm{eV}, 2.3 \mathrm{eV}$ respectively. The X-ray diffraction (XRD)Analysis shows the sol-gel spin coating deposited thin films are in crystalline nature and the average crystallite size of the CdS thin films measured is $9.25 \mathrm{~nm}$. From the Atomic force microscopy (AFM) analysis the corresponding CdS thin films roughness is measured and from the SEM analysis the surface morphology of the $\mathrm{CdS}$ thin films were determined. I-V characteristics of the CdS thin film were determined under $100 \mathrm{~W}$ visible lamp. And the Photo Response of the CdS thin films measured during light ON and light OFF intervals.

\section{References}

[1]. T. Peng, H.yang, k.dai, x. Pu and k. Hirao,.Chemical Physics letters 379 (2003)432-436.

[2]. Y. Kashiwaba , J. Sato , T. Abe ,. Applied surface science 212-213 (2003).

[3]. M.A. Mahdi, J.J. Hassan, N.M. Ahmed, S.S. Ng, Z. Hassan,.Super lattices and Microstructures 54 (2013) 137-145.

[4]. N.S Kozhevnikova, A .Rempel, F. Hergert and A. Magrel,.Thin Solid Films517 (2009) 2586-2589.

[5]. H.C. Chou and A.R. Ohatgi,.Journal of electronic Materials 23 (1994) 31.

[6]. L.S. Pedrotti and D.C. Reynolds,. Physical Review(1960) 1897.

[7]. Y.A. Kalandaragh, M.B. Muradov, R.K. Mammedov, A. Kaodayari, Growth process and investigation of some physical properties of CdSnanocrystals formed in polymer matrix by successive ionic layer adsorption and reaction (SILAR) method, Journal of Crystal Growth 305 (2007) 175-180.

[8]. M. Thambidurai, N. Muthukumarasamy, S. Agilin, S. Vasantha, R. BalasubramanyaPrabhu, Influence of the Cd/S molar ratio on the optical and structural properties of nano crystalline CdS thin films, Journal of Materials science and technology 26 (3) (2010) 193-199.

[9]. H. Moualkia, S. Hariech, M.S. Aida, Structural and Electrical Properties of CdS thin films grown by Chemical bath deposition, Thin solid films 518 (2009) 1259-1262.

[10]. T. Monde, H. Fukube, F. Nemoto, T. Yoko, T. Konakahara , Preparation and surface properties of silica-gel coating films containing branched -polyfluor-oalkylsilane, Journal of non-crystalline solids 246 (1999) 62-68.

[11]. T. Peng, H. Yang, k.Dai, X. Pu, K. Hirao, Chemical Physics letters 379(2003) 432-436.

[12]. L.A. Kosyachenko, A.I. Savchuk, E.V. Grushko, Thin solid films 517(2009) 2386-2391.

[13]. P. K . C, Pillai, N. shroff, A.K, Tripthi, A study of the photo conducting Properties of CdSe(cu) with a view to its use in solid - state image intensifiers, J. Physics, D: Appl. phy, vol.16, pp.393, 1983. 